EGU21-14473

https://doi.org/10.5194/egusphere-egu21-14473

EGU General Assembly 2021

(c) Author(s) 2022. This work is distributed under

the Creative Commons Attribution 4.0 License.

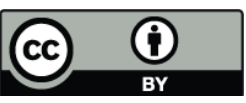

\title{
Slow subduction initiation drives fast mantle upwelling and lithosphere formation
}

Mathieu Soret ${ }^{1,2}$, Guillaume Bonnet ${ }^{3,4}$, Philippe Agard ${ }^{4}$, Kyle Larson ${ }^{1}$, John Cottle ${ }^{3}$, Benoit Dubacq ${ }^{4}$, Alexander Kylander-Clark ${ }^{3}$, Mark Button ${ }^{5}$, and Nicolas Rividi ${ }^{6}$

${ }^{1}$ Earth and Environmental Sciences, University of British Columbia Okanagan, 3247 University Way, Kelowna, British

Columbia, V1V 1V7, Canada.

${ }^{2}$ Institut des Sciences de la Terre d'Orléans (ISTO), UMR 7327, CNRS/BRGM, Université d'Orléans, 45071, Orléans, France.

${ }^{3}$ Department of Earth Science, University of California, Santa Barbara, Santa Barbara, CA93106, USA.

${ }^{4}$ Sorbonne Université, CNRS-INSU, Institut des Sciences de la Terre Paris, ISTeP UMR 7193, 75005 Paris, France.

${ }^{5}$ Fipke Laboratory for Trace Element Research, University of British Columbia Okanagan, Kelowna, BC, V1V 1V7, Canada.

${ }^{6}$ Sorbonne Université, OSU Ecce Terra, CAMPARIS Iaboratory, 75005 Paris, France.

Subduction zones are crucial features of Earth's plate tectonics, yet subduction initiation remains enigmatic and controversial. Herein, we reappraise the timing of formation of the first fragments detached from the leading edge of the downgoing slab during subduction initiation (i.e., the Semail metamorphic sole; Oman-United Arab Emirates). Based on geochronology and phase equilibrium modeling, we demonstrate that subduction initiated prior to $105 \mathrm{Ma}$ and at a slow pace $(<\mathrm{cm} / \mathrm{yr})$. Subduction stagnated at relatively warm conditions $\left(15-20^{\circ} \mathrm{C} / \mathrm{km}\right)$ for at least $10 \mathrm{Myr}$ before evolving into a faster ( $\left.\geq 2-5 \mathrm{~cm} / \mathrm{yr}\right)$ and colder $\left(\sim 7^{\circ} \mathrm{C} / \mathrm{km}\right)$ self-sustained regime. Subduction unlocking at 95-96 $\mathrm{Ma}$, through the progressive change of the interplate thermo-mechanical structure, triggered the onset of slab retreat, large-scale corner flow and fast ocean spreading in the overriding plate. These results reconcile conflicting analogue and numerical subduction initiation models and reveal the thermal, mechanical and kinematic complexity of early subduction steps. 